\title{
BMJ Open Association of GDF1 rs4808863 with fetal congenital heart defects: a case-control study
}

\author{
Juan Zhang, Qingqing Wu, Li Wang, Xiaofei Li, Yuqing Ma, Ling Yao
}

To cite: Zhang J, Wu Q, Wang $\mathrm{L}$, et al. Association of GDF1 rs4808863 with fetal congenital heart defects: a case-control study. BMJ Open 2015;5:e009352. doi:10.1136/bmjopen-2015009352

- Prepublication history for this paper is available online. To view these files please visit the journal online (http://dx.doi.org/10.1136/ bmjopen-2015-009352).

Received 9 July 2015 Revised 28 October 2015 Accepted 2 November 2015

CrossMark

Department of Ultrasound, Beijing Obstetrics and Gynecology Hospital, Capital Medical University, Beijing, China

Correspondence to Dr Qingqing Wu; wuqq2013@163.com

\section{ABSTRACT}

Background: Congenital heart defects (CHDs) are the most common fetal defects and the most important cause of child mortality and morbidity.

Objective: To investigate the association between growth/differentiation factor 1 (GDF1) polymorphisms and fetal CHDs, by evaluating the association of GDF1 rs4808863 with fetal CHDs.

Design: A case-control study.

Setting: Beijing, China.

Participants: We selected 124 fetuses with a CHD and a normal karyotype and normal array-based comparative genomic hybridisation analysis and compared them with 124 normal fetuses matched for gestational age and sex. Fetuses with a CHD, from 20 to 32 weeks of gestation were included. Fetuses with any chromosomal abnormalities, and fetuses from multiple pregnancies and those carried by pregnant women with chronic diseases, were excluded from this research. DNA extraction and genotyping were carried out for all cases to investigate the genotype distributions of GDF1 rs4808863.

Results: A significant difference was noted for the CT phenotype of GDF1 rs 4808863 between the controls and the fetuses with CHDs using homozygote and heterozygote comparisons. The minor allele (T allele) of GDF1 rs4808863 was associated with an increased risk of $\mathrm{CHD}(p<0.05)$. A statistically significant difference between controls and fetuses with CHDs was noted in a comparison with the mutation genotype $C T+$ TT and wild-type genotype CC $(p<0.05)$ using dominant modal analysis. After stratification analysis, the CT phenotype, the minor allele ( $T$ allele) and the mutation genotype CT+TT of the rs4808863 polymorphism were associated with atrioventricular septal defect (AVSD), left ventricular outflow tract obstruction (LVOTO) and left-right laterality defects $(\mathrm{p}<0.05)$.

Conclusions: Our results suggest that the GDF1 rs4808863 polymorphism contributes to an increased risk of fetal CHDs, especially the subtypes of AVSD, LVOTO and left-right laterality defects.

\section{INTRODUCTION}

Fetal congenital heart defects (CHDs) are defined as conditions with fetal cardiovascular dysplasia which affect, or may

\section{Strengths and limitations of this study}

- This study is the first to investigate the relationship between growth/differentiation factor 1 (GDF1) polymorphisms and fetal congenital heart defects (CHDs).

- The study group excluded individuals with chromosomal aberrations.

- Stratification analyses were performed to detect possible differences in fetal CHD subtypes.

- The main limitation is the small sample size of study participants. More individuals should be included in a future study.

- An additional limitation is that GDF1 is a member of the transforming growth factor- $\beta$ superfamily. More studies on the signalling pathway should be performed.

subsequently affect, cardiac function. CHDs are the most common fetal defects and the major cause of child mortality and morbidity. ${ }^{1}$

The aetiology of CHDs is not well understood. Earlier studies reported that genetic factors and environmental factors might play a major role in the occurrence and development of CHDs. Chromosomal aberrations are associated with the development of fetal CHD, but other multifactorial causes and genetic variants may play a part. $^{2}{ }^{3}$ Additionally, numerous signalling pathways mediate the development of CHDs, including the Notch signalling pathway, the transforming growth factor (TGF) $\beta$ signalling pathway and the Nodal signalling pathway. ${ }^{4}$ Previous studies have identified variable genes, members of CHD-associated signalling pathways and single-nucleotide polymorphisms (SNPs) that are associated with an increased risk for CHDs. ${ }^{6} 7$

Growth/differentiation factor 1 (GDF1), a member of the TGF- $\beta$ superfamily, was originally isolated from a day 8.5 mouse embryo cDNA library. ${ }^{8}$ GDF1 can affect organ morphogenesis and establish and maintain asymmetric cues. GDF1 signal mutations can 
regulate left-right patterning via the Nodal signalling pathway, resulting in CHDs, such as right atrial isomerism. ${ }^{910}$ Sun et al ${ }^{11}$ have shown that the GDF1 rs4808870 polymorphism is associated with an increased risk of pulmonary atresia in the Chinese Han population.

Severe CHDs are more likely to be detected before birth than minor CHDs. Women carrying fetuses with the most severe CHD are more likely to terminate the pregnancy given the poor outcome. ${ }^{12}$ Previous studies on the association between SNPs and CHDs were conducted in adult or child populations and little is known about GDF1 polymorphisms in fetuses with critical CHDs. Therefore, this study aimed to investigate the GDF1 gene SNP in Han Chinese fetuses with CHDs.

\section{MATERIALS AND METHODS}

Ethics statement

We performed a case-control study. This study was approved by the ethics committee of Beijing Obstetrics and Gynecology Hospital, Capital Medical University. Each patient provided written informed consent to participate in this study.

\section{Study population}

We selected 124 sporadic fetuses with CHDs as the case group and 124 unrelated normal fetuses, matched for gestational age and gender, as the control group. All the cases of CHD were diagnosed in Beijing Obstetrics and Gynecology Hospital, Capital Medical University between January 2012 and December 2014. Inclusion criteria required that the fetuses were 20-32 weeks and had a CHD. All fetuses received a routine anomaly ultrasound scan in the second trimester, and echocardiography (Voluson E8, GE Healthcare, Milwaukee, Wisconsin USA) was performed when fetuses were found to exhibit a heart abnormality. The diagnosis of CHD was made by two fetal echocardiologists. Karyotype analysis and array comparative genome hybridisation were performed for all fetuses. Cases with any chromosomal abnormalities, such as trisomy syndrome and pathogenic copy number variants, were excluded. Fetuses from multiple pregnancies and those carried by pregnant women with chronic diseases (such as gestational diabetes mellitus, chronic alcoholism and connective tissue diseases) were excluded from this research.

\section{Single nucleotide polymorphism selection}

GDF1 (OMIM: 602880) maps to chromosome 19p13.11. After a small sample study, we found that the rs4808863 SNP (NM_001492.5:c.353C $>$ T) presented genetic variants. We searched for the GDF1 rs4808863 SNP in the Ensembl genome browser (http://www.ensembl.org/ index.html) and information was obtained from the SNP database. The Ensembl genome browser showed that the allele change of rs4808863 was Ala $\rightarrow$ Val $(\mathrm{GCC} \rightarrow \mathrm{GTC})$, so we selected exon 8 including SNP rs4808863 as our research object.

\section{DNA extraction and genotyping}

We obtained umbilical cord blood by fetal blood sampling at the time of labour induction in the CHD group and after delivery of the baby, in the control group. All patients provided $2 \mathrm{~mL}$ samples of umbilical cord blood that were collected in Vacutainer tubes containing EDTA by invasive testing. We used the blood genomic DNA extraction kit (Be creative Lab (Beijing) Co Ltd, Beijing, China), according to the manufacturer's instructions. SNP genotyping was conducted by direct sequencing. PCRs were performed using specific primers for the GDF1 SNPs. Primers were designed by Primer Premier and Oligo as presented in table 1. PCR was performed in a $25 \mu \mathrm{L}$ total volume reaction mixture containing $1.0 \mu \mathrm{L}$ genomic DNA, $0.3 \mu \mathrm{L}$ Taq polymerase $(5 \mathrm{U} / \mu \mathrm{L})$ (Omega Genetics Co Ltd, Beijing, China), $0.4 \mu \mathrm{L}$ dNTPs $(10 \mathrm{mM}), 0.5 \mu \mathrm{L}$ of each primer, $0.62 \mu \mathrm{L} 10 \times$ buffer (Mg2+Plus), 9.37 $\mu \mathrm{L} 2 \times$ GC buffer I and $12.31 \mu \mathrm{L}$ double distilled water). The PCR reaction consisted of an initial denaturation step at $95^{\circ} \mathrm{C}$ for $5 \mathrm{~min} ; 5$ cycles at $94^{\circ} \mathrm{C}$ for $30 \mathrm{~s}, 68^{\circ} \mathrm{C}$ for $30 \mathrm{~s}$ and $72^{\circ} \mathrm{C}$ for $1 \mathrm{~min} ; 12$ cycles at $94^{\circ} \mathrm{C}$ for $30 \mathrm{~s}, 65^{\circ} \mathrm{C}$ for $30 \mathrm{~s}$ and $72^{\circ} \mathrm{C}$ for $1 \mathrm{~min} ; 12$ cycles at $94^{\circ} \mathrm{C}$ for $30 \mathrm{~s}, 60^{\circ} \mathrm{C}$ for $30 \mathrm{~s}$ and $72^{\circ} \mathrm{C}$ for $1 \mathrm{~min} ; 10$ cycles at $94^{\circ} \mathrm{C}$ for $30 \mathrm{~s}, 55^{\circ} \mathrm{C}$ for $30 \mathrm{~s}, 72^{\circ} \mathrm{C}$ for $1 \mathrm{~min}$ and an additional extension at $72^{\circ} \mathrm{C}$ for $7 \mathrm{~min}$ in a thermal cycler. We used an ABI Prism $3730 \mathrm{xl}$ sequencer (Applied Biosystems, Foster City, California, USA) to sequence the PCR products after purification.

\section{Statistical analysis}

All statistical computations were performed using the SPSS statistical software package (V.17.0 for Windows, SPSS Inc, Chicago, Illinois, USA). p Values $<0.05$ were considered statistically significant. Allele frequencies were assessed for Hardy-Weinberg equilibrium using the $\chi^{2}$ test or Fisher's exact test. The differences in the genotype frequencies between the two groups were also assessed using these tests.

\section{RESULTS}

\section{GDF1 SNP rs4808863 genotype distribution}

Successful genotyping of rs4808863 in CHDs was not achieved in three cases. We identified two alleles $(\mathrm{C}$ and T) and three genotypes (CC, CT and TT) at rs4808863 (figure 1).

As presented in table 2, the distribution of genotype frequencies in both the CHDs $(n=121)$ and the controls $(n=124)$ were in Hardy-Weinberg equilibrium $(\mathrm{p}>0.05)$. In our controls, the genotype distributions and minor allele frequencies of GDF1 SNP rs4808863 were similar to the Han Chinese in Beijing genotype data in the HapMap database.

Association between genotype and allele frequencies of GDF1 SNP rs4808863 in fetuses with CHD and controls The rs4808863 CC, CT and TT genotype distributions in CHD cases and controls are presented in table 3. The 
Table 1 Primers for GDF1 exon 8

\begin{tabular}{lllll}
\hline Primer name & Primer sequence & $\begin{array}{l}\text { Sequence amplified } \\
\text { regions (GRCh38) }\end{array}$ & $\begin{array}{l}\text { Amplified fragment } \\
\text { length (bp) }\end{array}$ & GC \\
\hline GDF1-8F & CCCCAGCGTTCACCTTCCTC & chr19:18868321-18869484 & 1164 & $74 \%$ \\
GDF1-8R & AGACAGGCAAAGCCCAGAAGG & & & \\
\hline Primers were designed by Primer Premier and Oligo. & &
\end{tabular}

frequencies of GDF1 rs4808863 genotypes were 58.6\% (CC), 39.7\% (CT) and $1.7 \%$ (TT) in CHD fetuses and $76.6 \%$ (CC), $21.0 \%$ (CT) and 2.4\% (TT) in control subjects. The CT genotype frequency of rs4808863 in fetuses with CHDs differed significantly from that of the controls $(\mathrm{p}=0.002)$. The frequency of the minor $\mathrm{T}$ allele of rs4808863 was significantly increased in the CHD cases compared with healthy controls $(\mathrm{p}=0.012$, $\mathrm{OR}=1.847$, 95\% CI 1.141 to 2.990 ). However, we found no significant differences in the TT genotype in CHD cases compared with healthy controls. According to dominant model analysis between controls and CHD cases, a statistically significant difference was found for the mutation genotypes CT+TT and wild-type genotype CC $(p=0.003, O R=2.307,95 \%$ CI 1.329 to 4.003$)$.

\section{Stratified subgroup analysis of GDF1 SNP rs4808863}

Eight major groups of human heart malformations have been reported, including conotruncal defects (CTDs); atrioventricular septal defects (AVSD); anomalous pulmonary venous return (APVR); left ventricular outflow tract obstruction (LVOTO); right ventricular outflow tract obstruction (RVOTO); and septal, heterotaxy and complex (table 4). ${ }^{13}$

We analysed the genotypes and allele frequencies of the GDF1 rs4808863 SNP in different subgroups of CHDs (table 5). The results showed that the rs 4808863 CT genotype was associated with an increased risk of AVSD and LVOTO compared with healthy controls
( $\mathrm{p}=0.001, \mathrm{OR}=7.308,95 \%$ CI 2.296 to $23.261 ; \mathrm{p}=0.018$, $\mathrm{OR}=4.176,95 \%$ CI 1.386 to 12.586 , respectively). In addition, the frequency of the $\mathrm{T}$ allele also significantly differed in patients with AVSD and LVOTO compared with healthy controls $(\mathrm{p}=0.007, \mathrm{OR}=3.375,95 \%$ CI 1.450 to $7.857 ; \mathrm{p}=0.013, \quad \mathrm{OR}=3.068,95 \%$ CI 1.332 to 7.069 ; respectively). Moreover, dominant model analyses of the subtypes of CHD, such as AVSD and LVOTO, exhibited significant difference $(\mathrm{p}=0.001, \mathrm{OR}=6.552,95 \%$ CI 2.072 to $20.717 ; \mathrm{p}=0.013$, OR=4.212, $95 \%$ CI 1.442 to 12.300 ; respectively).

However, no significant differences in rs4808863 genotypes, alleles and dominant models were noted in the analysis among the various subtypes, including CTDs, APVR, RVOTO, septal patients, heterotaxy, complex cases and controls.

\section{DISCUSSION}

CHD is a major cause of neonatal morbidity and mortality. ${ }^{1}$ To explore the potential mechanisms involved in fetal CHDs, we investigated the association of GDF1 rs4808863 and the risk of fetal CHDs in our study. We found that the minor $\mathrm{T}$ allele, the CT phenotype and dominant models of rs4808863 were significantly associated with susceptibility to CHDs, especially for two subtypes, AVSD and LVOTO. The results suggest that fetuses with the CT phenotype may be more easily affected by AVSD and LVOTO. Additionally, the inheritance patterns of GDF1 in AVSD and LVOTO may tend to exhibit
Figure 1 Partialsequence analysis of rs4808863 genotypes. (A) CC genotype. (B) TT genotype. (C) CT genotype.

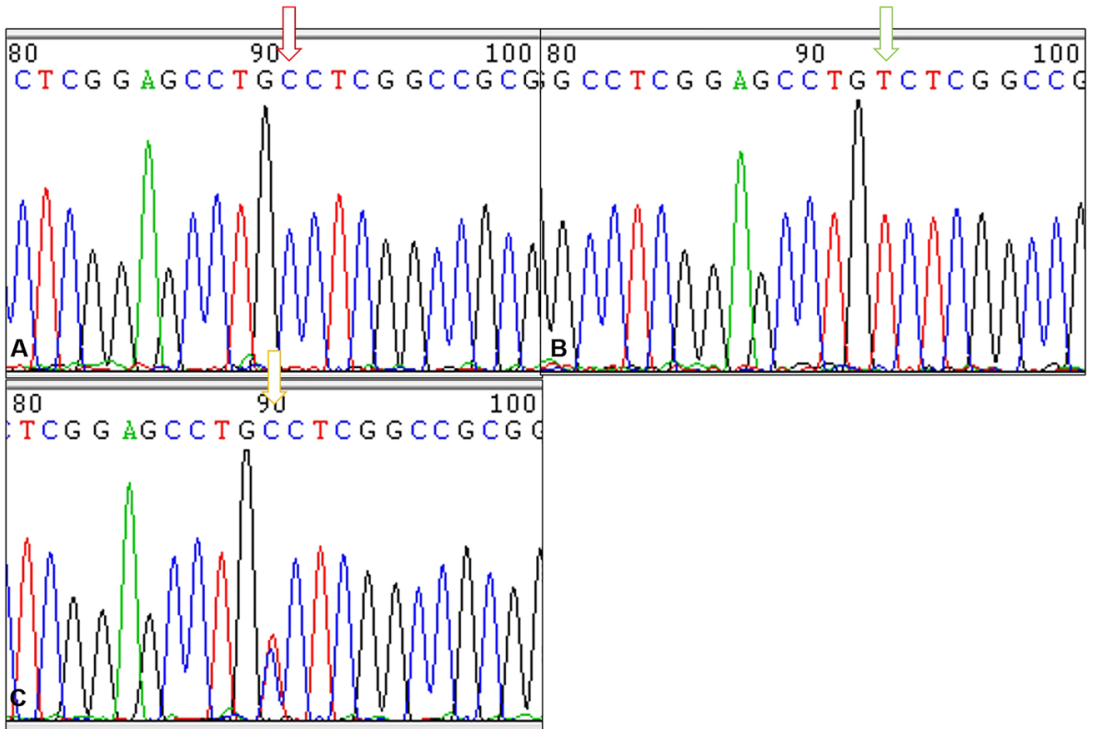


Table 2 Hardy-Weinberg equilibrium of GDF1 SNP rs4808863 allele frequencies

\begin{tabular}{|c|c|c|c|c|c|c|}
\hline \multirow[b]{2}{*}{ SNP } & \multirow[b]{2}{*}{ Group } & \multicolumn{3}{|c|}{ Genotype } & \multirow[b]{2}{*}{$\chi^{2}$} & \multirow[b]{2}{*}{ p Value } \\
\hline & & $\overline{\mathbf{C C}}$ & CT & TT & & \\
\hline \multirow[t]{2}{*}{ rs4808863 } & CHDs & 71 & 48 & 2 & 3.74 & 0.053 \\
\hline & Controls & 95 & 26 & 3 & 0.02 & 0.886 \\
\hline
\end{tabular}

dominant models. In our study, no significant difference in the frequency of the TT genotype was noted between controls and those with CHDs, suggesting that the homozygous mutation might not be associated with CHDs. Bengtsson et $a l^{14}$ reported that GDF1 null mice die during late embryogenesis. This phenomenon may explain the small sample size of the TT phenotype in the CHD cases.

As a member of the TGF- $\beta$ superfamily, GDF1 was mapped to chromosome 19p13.11. ${ }^{8}$ GDF1 is homologous to Vg-1 in Xenopus and Dvr1 in zebrafish based on accumulating evidence. ${ }^{15} 16$ Northern (RNA) analysis of GDF1 transcripts in murine embryonic mRNA detected two mRNA species 1.4 and $3.0 \mathrm{~kb}$ in length and only the $3.0 \mathrm{~kb}$ mRNA species persists throughout embryogenesis. ${ }^{17}$

In our study, GDF1 rs4808863 was mapped to exon 8 of GDF1. Recent studies have shown that GDF1 mutations are present in cardiovascular malformations, such as tetralogy of Fallot (TOF) and transposition of the great arteries (TGA). GDF1 also potentially decreases TGF- $\beta$ signalling to cause some specific types of human CHDs. ${ }^{18} 19$ To date, GDF1 mutations are reportedly involved in recessively inherited right atrial isomerism. ${ }^{10}$ Our study showed that rs4808863 GDF1 polymorphism is associated with AVSD and LVOTO and these findings are not consistent with these studies. Furthermore, Sun et $a l^{11}$ suggested that the GDF1 polymorphism might be associated with an increased risk of CTDs. However, De
Table 4 Details of the eight major subgroups of CHDs

\begin{tabular}{ll}
\hline Groups & Details \\
\hline CTDs $(n=56)$ & $\begin{array}{l}\text { Tetralogy of Fallot } \\
\text { Transposition of the great arteries } \\
\text { Double outlet right ventricle } \\
\text { Truncus arteriosus } \\
\text { Interrupted aortic arch }\end{array}$ \\
AVSD ( $=15)$ & $\begin{array}{l}\text { Primum type atrial septal defect } \\
\text { AVSD }\end{array}$ \\
APVR $(n=4)$ & $\begin{array}{l}\text { Total APVR } \\
\text { Partial APVR }\end{array}$ \\
LVOTO & $\begin{array}{l}\text { Hypoplastic left heart syndrome } \\
\text { Aortic stenosis } \\
\text { Aortic coarctation }\end{array}$ \\
RVOTO $(n=6)$ & $\begin{array}{l}\text { Hypoplastic right heart syndrome } \\
\text { Tricuspid atresia }\end{array}$ \\
Ebstein
\end{tabular}

APVR, anomalous pulmonary venous return; AVSD, atrioventricular septal defects; CHDs, congenital heart defects; CTDs, conotruncal defects; LVOTO, left ventricular outflow tract obstruction; RVOTO, right ventricular outflow tract obstruction.

Luca $e t a l^{20}$ investigated the prevalence of GDF1 mutations in patients with CTD and the results presented a contrasting view. No GDF1 mutations were noted in CTD, indicating that GDF1 is not a good candidate for CTDs.

In our study, we found that the GDF1 polymorphism is related to the non-CTD subtype, which is consistent with De Luca's study but differs from the research of Sun. CTDs, a group of abnormal great artery and outflow tract defects, account for about $15-20 \%$ of

Table 3 Genotype and allele frequencies of GDF1 SNP rs4808863 in controls and fetuses with CHD

\begin{tabular}{|c|c|c|c|c|c|}
\hline \multirow[b]{2}{*}{ Genotype/allele } & \multicolumn{2}{|c|}{$\begin{array}{l}\text { Genotype/allele } \\
\text { frequency }\end{array}$} & \multirow[b]{2}{*}{$\chi^{2}$} & \multirow[b]{2}{*}{ p Value } & \multirow[b]{2}{*}{ OR (95\% Cl) } \\
\hline & CHDs & Controls & & & \\
\hline $\mathrm{CC}$ & 71 & 95 & - & - & - \\
\hline CT & 48 & 26 & 9.994 & 0.002 & 2.47 (1.400 to 4.358$)$ \\
\hline TT & 2 & 3 & 0.015 & $1.000^{*}$ & $0.892(0.145$ to 5.480$)$ \\
\hline C & 190 & 216 & - & - & - \\
\hline $\mathrm{T}$ & 52 & 32 & 6.354 & 0.012 & 1.847 (1.141 to 2.990$)$ \\
\hline $\mathrm{CT}+\mathrm{TT}$ & 50 & 29 & 9.017 & 0.003 & 2.307 (1.329 to 4.003$)$ \\
\hline $\mathrm{CC}+\mathrm{CT}$ & 119 & 121 & 0.180 & $1.000^{*}$ & 1.475 (0.242 to 8.98$)$ \\
\hline
\end{tabular}

${ }^{*} p$ Value from adjusted $\chi^{2}$ tests with continuity correction.

Significant differences between cases and controls are shown in bold.

CC, CT and TT are genotypes of GDF1 SNP rs4808863. C and T are alleles at rs4808863. CT+TT, dominant model; CC+CT, recessive model.

CHDs, congenital heart defects; SNPs, single-nucleotide polymorphisms. 


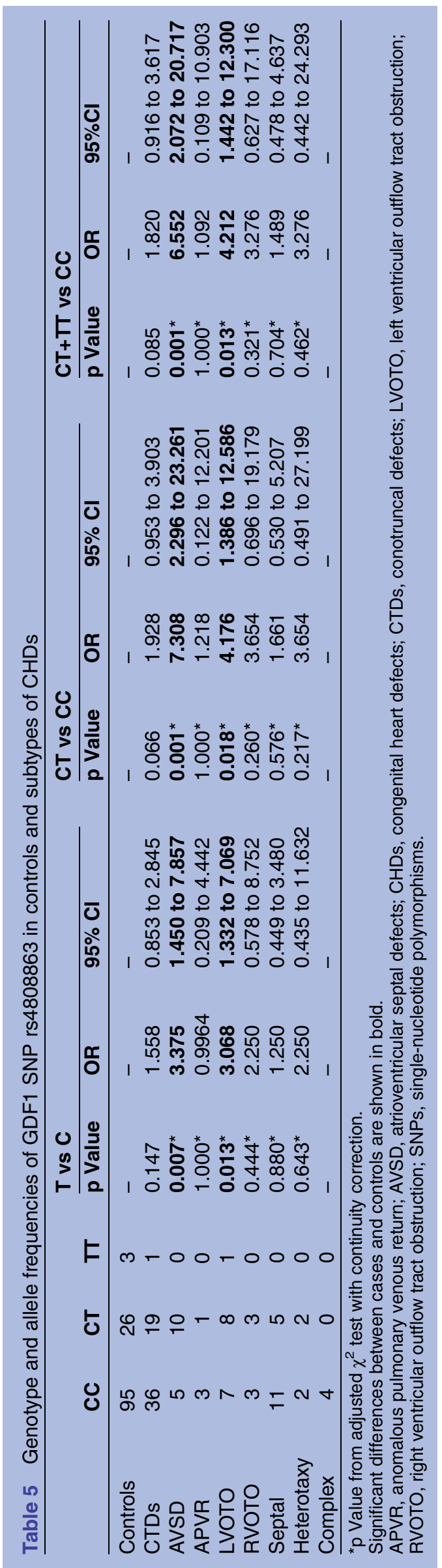

CHDs. CTDs include TOF, TGA, double outlet right ventricle (DORV), interruption of the aortic arch, pulmonary atresia, persistent truncus arteriosus and atriopulmonary window. ${ }^{13}$ In Sun's study, a correlations was found between GDF1 and the risk of pulmonary atresia. However, no cases of pulmonary atresia were included in our study. Therefore, the findings of our study are similar to those of both Sun and De Luca. Based on these data, GDF1 might not be associated with CTDs, especially in the clinical phenotypes of TOF, TGA and DORV. On the other hand, in comparison with other studies, our study focused on a different polymorphism site, a different population and more severe clinical phenotypes of CHDs. These differences might be the main reasons for the different result.

The mechanism by which GDF1 is involved in CHD remains unclear. However, several previous studies have investigated the potential mechanism. Baker et $a l^{21}$ studied cardiac development in zebrafish and found that zebrafish heart development undergoes first, the process of cardiac jogging and second, asymmetry of cardiac looping. The Nodal signalling pathway may establish cardiac laterality by influencing the second asymmetry of cardiac looping. TGF- $\beta$ signalling is critically important for the morphogenesis of atrioventricular cushions. ${ }^{22}$ As a member of the TGF- $\beta$ superfamily, GDF1 was first identified by Lee as the first molecule involved in organising left-right axis formation to regulate the Nodal pathway by heterodimerising with Nodal. ${ }^{8}{ }^{23}{ }^{24}$ Shen $^{22}$ observed that the Nodal signalling pathway plays a critical role in normal embryogenesis and is especially important in the formation of the human heart. During the process of Nodal signal transduction, the heterodimerisation of GDF1 and Nodal stimulate activin receptor signalling. Then, type I and type II activin receptors activate the phosphorylation of Smad2 and Smad3. Next, Smad2 and Smad3 cooperate with Smad4 to translocate into the nucleus. The Smad complex binds DNA or DNA binding protein to prime the expression of tissuespecific genes. ${ }^{25}{ }^{26}$ In addition, Zhang $e t a l^{27}$ demonstrated that GDF1 plays a critical role in cardiac remodelling via the MEK-ERK1/2 and Smad signalling pathways. We hypothesise that GDF1 may play a role in CHD via these two signalling pathways, but more research is needed to verify this hypothesis.

By establishing mouse models with a targeted mutation in GDF1, researchers have shown that GDF1 is implicated in the establishment of left-right asymmetry. Mutant mice exhibited a range of congenital anomalies, such as CHD and visceral situs inversus. ${ }^{28}$

GDF1 is one of the known susceptibility genes for CHD, but the incidence of GDF1 SNPs had not been previously explored in the Chinese Han population. Our group designed this study to analyse the association between the GDF1 rs4808863 SNP and CHD. The study design enabled us to complete the experiment by using inexpensive instrumentation and reagents. In summary, our study demonstrated that GDF1 rs4808863 was 
associated with an increased risk of fetal CHDs, especially AVSD and LVOTO. However, the main limitation of our study is the small sample size and a larger study should be conducted in the future. An additional limitation is that GDF1 is a member of the TGF- $\beta$ superfamily and more studies on the signalling pathway should be performed. Although this study provides a basis for further investigation of the biological role of GDF1 in the development of fetal CHDs, further studies need to explore the molecular mechanisms of the interaction between GDF1 and fetal CHDs.

Acknowledgements We thank all participants in the study and Xinli Huang for his support. In addition, we thank American Journal Experts for help with the language.

Contributors QW designed the study. JZ, QW, LW, XL, YM and LY collected human samples and clinical data. JZ conducted the statistical analysis of the data. JZ and QW wrote the paper.

Funding This work was supported by the National Nature Science Foundation of China (81071159), Beijing Municipal Science and Technology Commission (No Z141107002514006) and Beijing Municipal Administration of Hospital Clinical Medicine Development of Special Foundation (XMLX201310).

Competing interests None declared.

Patient consent Obtained.

Ethics approval The study was approved by the ethics committee of Beijing Obstetrics and Gynecology Hospital, Capital Medical University.

Provenance and peer review Not commissioned; externally peer reviewed.

Data sharing statement No additional data are available.

Open Access This is an Open Access article distributed in accordance with the Creative Commons Attribution Non Commercial (CC BY-NC 4.0) license, which permits others to distribute, remix, adapt, build upon this work noncommercially, and license their derivative works on different terms, provided the original work is properly cited and the use is non-commercial. See: http:// creativecommons.org/licenses/by-nc/4.0/

\section{REFERENCES}

1. van der Bom $\mathrm{T}$, Zomer $\mathrm{AC}$, Zwinderman $\mathrm{AH}$, et al. The changing epidemiology of congenital heart disease. Nat Rev Cardiol 2011;8:50-60.

2. Srivastava D, Olson EN. A genetic blueprint for cardiac development. Nature 2000;407:221-6.

3. Polli JB, Groff Dde P, Petry P, et al. Trisomy 13 (Patau syndrome) and congenital heart defects. Am J Med Genet A 2014;164A:272-5.

4. Paige SL, Plonowska $\mathrm{K}, \mathrm{Xu} \mathrm{A}$, et al. Molecular regulation of cardiomyocyte differentiation. Circ Res 2015:116:341-53.

5. Bisgrove BW, Essner JJ, Yost HJ. Multiple pathways in the midline regulate concordant brain, heart and gut left-right asymmetry. Development 2000;127:3567-79.

6. Cooper GM, Coe BP, Girirajan S, et al. A copy number variation morbidity map of developmental delay. Nat Genet 2011;43:838-46.
7. Yan $\mathrm{Y}, \mathrm{Wu} \mathrm{Q}$, Zhang $\mathrm{L}$, et al. Detection of submicroscopic chromosomal aberrations by array-based comparative genomic hybridization in fetuses with congenital heart disease. Ultrasound Obstet Gynecol 2014:43:404-12.

8. Lee SJ. Identification of a novel member (GDF-1) of the transforming growth factor-beta superfamily. Mol Endocrinol 1990;4:1034-40.

9. Wall NA, Craig EJ, Labosky PA, et al. Mesendoderm induction and reversal of left-right pattern by mouse Gdf1, a Vg1-related gene. Dev Biol 2000;227:495-509.

10. Kaasinen $\mathrm{E}$, Aittomäki K, Eronen $\mathrm{M}$, et al. Recessively inherited right atrial isomerism caused by mutations in growth/differentiation factor 1 (GDF1). Hum Mol Genet 2010;19:2747-53.

11. Sun $X$, Meng $Y$, You T, et al. Association of growth/differentiation factor 1 gene polymorphisms with the risk of congenital heart disease in the Chinese Han population. Mol Biol Rep 2013;40:1291-9.

12. Oster ME, Kim CH, Kusano AS, et al. A population-based study of the association of prenatal diagnosis with survival rate for infants with congenital heart defects. Am J Cardiol 2014;113:1036-40.

13. Botto LD, Lin AE, Riehle-Colarusso T, et al. National Birth Defects Prevention Study. Seeking causes: classifying and evaluating congenital heart defects in etiologic studies. Birth Defects Res A Clin Mol Teratol 2007;79:714-27.

14. Bengtsson H, Epifantseva I, Abrink M, et al. Generation and characterization of a Gdf1 conditional null allele. Genesis 2008;46:368-72.

15. Dohrmann CE, Kessler DS, Melton DA. Induction of axial mesoderm by zDVR-1, the zebrafish orthologue of Xenopus Vg1. Dev Biol 1996;175:108-17.

16. Li X, Ma Y, Li D, et al. Arsenic impairs embryo development via down-regulating Dvr1 expression in zebrafish. Toxicol Lett 2012;212:161-8.

17. Lee SJ. Expression of growth/differentiation factor 1 in the nervous system: conservation of a bicistronic structure. Proc Natl Acad Sci USA 1991:88:4250-4

18. Karkera JD, Lee JS, Roessler E, et al. Loss-of-function mutations in growth differentiation factor-1 (GDF1) are associated with congenital heart defects in humans. Am J Hum Genet 2007;81:987-94.

19. Azhar M, Runyan RB, Gard C, et al. Ligand-specific function of transforming growth factor beta in epithelial-mesenchymal transition in heart development. Dev Dyn 2009;238:431-42.

20. De Luca A, Sarkozy A, Ferese R, et al. New mutations in ZFPM2/ FOG2 gene in tetralogy of Fallot and double outlet right ventricle. Clin Genet 2011;80:184-90.

21. Baker K, Holtzman NG, Burdine RD. Direct and indirect roles for nodal signaling in two axis conversions during asymmetric morphogenesis of the zebrafish heart. Proc Natl Acad Sci USA 2008;105:13924-9.

22. Shen MM. Nodal signaling: developmental roles and regulation. Development 2007;134:1023-34.

23. Tanaka $C$, Sakuma $R$, Nakamura $T$, et al. Long-range action of nodal requires interaction with GDF1. Genes Dev 2007;21:3272-82.

24. Andersson $\mathrm{O}$, Reissmann $\mathrm{E}$, Jörnvall $\mathrm{H}$, et al. Synergistic interaction between Gdf1 and nodal during anterior axis development. Dev Biol 2006;293:370-81.

25. Arnold SJ, Robertson EJ. Making a commitment: cell lineage allocation and axis patterning in the early mouse embryo. Nat Rev Mol Cell Biol 2009;10:91-103.

26. Fuerer C, Nostro MC, Constam DB. Nodal.Gdf1 heterodimers with bound prodomains enable serum-independent nodal signaling and endoderm differentiation. J Biol Chem 2014;289:17854-71.

27. Zhang Y, Zhang XF, Gao L, et al. Growth/differentiation factor 1 alleviates pressure overload-induced cardiac hypertrophy and dysfunction. Biochim Biophys Acta 2014;1842:232-44.

28. Rankin CT, Bunton T, Lawler AM, et al. Regulation of left-right patterning in mice by growth/differentiation factor-1. Nat Genet 2000;24:262-5. 